\title{
Inhibition of RNA polymerase III transcription by Triptolide attenuates colorectal tumorigenesis
}

\author{
Xia Liang ${ }^{1 \dagger}$, Renxiang Xie ${ }^{2 \dagger}$, Jinfeng $\mathrm{Su}^{1 \dagger}$, Bingqi Ye ${ }^{2}$, Saisai Wei ${ }^{3}$, Zhibing Liang ${ }^{1}$, Rongpan Bai ${ }^{2}$, Zhanghui Chen ${ }^{4}$, \\ Zhongxiang $\mathrm{Li}^{\mathrm{i}^{*}}$ and Xiangwei $\mathrm{GaO}^{2^{*}}$
}

\begin{abstract}
Background: Upregulation of RNA polymerase (Pol) III products, including tRNAs and 5S rRNA, in tumor cells leads to enhanced protein synthesis and tumor formation, making it a potential target for cancer treatment. In this study, we evaluated the inhibition of Pol III transcription by triptolide and the anti-cancer effect of this drug in colorectal tumorigenesis.

Methods: The effect of triptolide on colorectal cancer development was assessed in colorectal cancer mouse models, 3D organoids, and cultured cells. Colorectal cancer cells were treated with triptolide. Pol III transcription was measured by realtime quantitative polymerase chain reaction (PCR). The formation of TFIIIB, a multi-subunit transcription factor for Pol III, was determined by chromatin immunoprecipitation (ChIP), co-immunoprecipitation (Co-IP), and fluorescence resonance energy transfer (FRET).

Results: Triptolide reduced both tumor number and tumor size in adenomatous polyposis coli (Apc) mutated (Apc ${ }^{\mathrm{Min} /+}$ ) mice as well as AOM/DSS-induced mice. Moreover, triptolide effectively inhibited colorectal cancer cell proliferation, colony formation, and organoid growth in vitro, which was associated with decreased Pol III target genes. Mechanistically, triptolide treatment blocked TBP/Brflinteraction, leading to the reduced formation of TFIIIB at the promoters of tRNAs and $5 S$ rRNA.

Conclusions: Together, our data suggest that inhibition of Pol III transcription with existing drugs such as triptolide provides a new avenue for developing novel therapies for colorectal cancer.
\end{abstract}

Keywords: Triptolide, Colorectal cancer, RNA polymerase III, TFIIIB

\section{Background}

Colorectal cancer (CRC) is the third most common cause of cancer-related deaths worldwide [1]. Despite significant progress in the prevention, early diagnosis and management of CRC, the clinical outcome for advanced CRC is unsatisfactory [1]. Chemotherapy compounds such as 5-FU and oxaliplatin are well established in reducing recurrence and prolonging survival, especially for later stage patients. However, the systemic

\footnotetext{
* Correspondence: zhongxiangli@gmail.com; xiangweigao@zju.edu.cn ${ }^{+}$Xia Liang, Renxiang Xie and Jinfeng Su contributed equally to this work. 'Medical Research Institute, \& Guangdong Women and Children's Disease Precision Diagnosis and Treatment Engineering Technology Research Center, Baoan Maternal and Child Health Hospital, Jinan University, Shenzhen 518102, China

2Department of Public Health, Zhejiang University School of Medicine, Hangzhou 310058, China

Full list of author information is available at the end of the article
}

toxicity caused by chemotherapy and the development of drug resistance are major obstacles for the success of CRC chemotherapy [2]. Thus, the development of novel anticancer drugs or therapeutics is urgently needed.

Triptolide is a diterpene triepoxide purified from Tripterygium wilfordii Hook F, commonly known as lei gong teng or thunder god vine, a medicinal plant whose extracts have been used in traditional Chinese medicine for treating rheumatoid arthritis and other inflammatory diseases [3]. Recent studies have shown that triptolide kills a variety of cancer cell lines including colorectal cancer cells in vitro with high potency [4]. Animal studies have shown that triptolide inhibits the growth of colorectal cancer cells in a mouse xenograft model [5]. However, cell lines do not reflect the complexity of in vivo tumor growth condition, while xenograft model may not represent the real context of colorectal carcinogenesis. Apc ${ }^{\mathrm{Min} /+}$ mouse, carrying a

(C) The Author(s). 2019 Open Access This article is distributed under the terms of the Creative Commons Attribution 4.0 International License (http://creativecommons.org/licenses/by/4.0/), which permits unrestricted use, distribution, and 
truncation mutation at the tumor suppressor gene $A p c$, is a frequently used genetic mouse model for the study of familial adenomatous polyposis (FAP) and early events of CRC [6]. Genotoxic colonic carcinogen such as azoxymethane $(\mathrm{AOM})$ is routinely used to induce colon tumors in mice [7]. The combination of AOM and dextran sodium sulfate (DSS) is frequently used to investigate the development of colitis-associated cancer (CAC) [8]. Therefore, evaluation of the anti-cancer effects of triptolide using these colorectal carcinogenesis mouse models will promote its clinical applications for CRC treatment.

The anticancer effect of triptolide was attributed to its inhibition on transcription [9]. It was reported that triptolide targets the transcription factor XPB and RNA polymerase (Pol) II to inhibit Pol II-mediated mRNA transcription $[10,11]$. XPB, a subunit of the general transcription factor TFIIH, is involved in both RNAPII-mediated transcription initiation and DNA nucleotide excision repair. Triptolide directly binds to XPB, inhibits its ATPase activity and consequently, represses RNAPII transcription initiation and nucleotide excision repair [10]. On the other hand, triptolide induces the degradation of Rpb1, the largest subunit of RNA polymerase II [11]. It was also reported that triptolide disrupts nucleolar integrity and inhibits Pol I-mediated ribosomal RNA transcription [12]. Therefore, triptolide acts as an inhibitor of both Pol I and Pol II.

Pol III, the third type of RNA polymerase, transcribes a variety of untranslated RNAs, including tRNAs, 5S rRNA, 7SL RNA, 7SK RNA and U6 RNA [13], whereas tRNAs and 5S rRNA control mRNA translation efficiency and growth capacity of cells $[14,15]$. Polymerase III transcription is mediated by TFIIIB complex, consisting of TATA box-binding protein (TBP) and its associated factors B-related factor 1 (Brf1), and B double prime 1 (Bdp1). TFIIIB, together with TFIIIC and RNA Pol III, mediate tRNAs transcription, whereas TFIIIB, together with TFIIIA, TFIIIC and RNA Pol III, mediate 5S rRNA genes transcription [16]. Studies have indicated that RNA Pol III products are elevated in both transformed and tumor cells, suggesting that they have a crucial role in tumorigenesis [14, 17]. Consistent with this idea, enhanced Pol III transcription is required for oncogenic transformation [18]. However, whether triptolide could target Pol III transcription remains to be identified.

In this study, we systematically evaluated triptolide as a therapeutic option for the treatment of colorectal cancer in both $\mathrm{Apc}^{\mathrm{Min} /+}$ and AOM/DSS mice. Additionally, our data revealed the inhibitory effect of triptolide on Pol III transcription, which has important implications in the application of triptolide for CRC treatment.

\section{Materials and methods}

\section{Mouse treatment}

To evaluate the effect of triptolide on tumorigenesis in vivo, both $\mathrm{AOM} / \mathrm{DSS}$ and $\mathrm{Apc} \mathrm{Min} /+^{\mathrm{m}}$ mouse CRC models were used. For the AOM/DSS model, eight-week-old wild type female C57BL/6 J mice were first injected with 10 $\mathrm{mg} / \mathrm{kg}$ AOM intraperitoneally 1 week prior to the first of three DSS cycles. After the formation of tumors (usually 8 weeks after AOM treatment), mice were randomly divided into two groups and intraperitoneal administrated with either $0.5 \mathrm{mg} / \mathrm{kg}$ of triptolide in dimethyl sulfoxide (DMSO) or DMSO (solvent only, control group) twice a week. The mice were sacrificed at 12-week of age and the number of tumors was assessed. The diameter of the tumors was measured and categorized them to 3 groups: small $(<2 \mathrm{~mm})$, middle $(2-4 \mathrm{~mm})$, and large $(>4 \mathrm{~mm})$. Six mice were used for each group.

The $\mathrm{Apc}^{\mathrm{Min} /+}$ mice, carrying a truncated mutation of the Apc gene, develop spontaneous intestinal tumors [6]. After the formation of tumors (usually happens at 3 months of age), the $\mathrm{Apc}^{\mathrm{Min} /+}$ mice were randomly divided into two groups and treated with either $0.5 \mathrm{mg} / \mathrm{kg}$ of triptolide in DMSO or DMSO (solvent only, control group) twice a week. The mice were sacrificed at six-month of age and the number, size of tumors was assessed. Seven mice were used for each group.

Mice were maintained and bred in specific pathogen-free conditions at the Animal Center of Zhejiang University. All animal studies were performed in compliance with the Guide for the Care and Use of Laboratory Animals by the Medical Experimental Animal Care Commission of Zhejiang University. All animal studies used the protocol that has been approved by the Medical Experimental Animal Care Commission of Zhejiang University.

\section{Organoid culture and ATP measurement}

The crypt was isolated from the $\mathrm{Apc}^{\mathrm{Min} /+}$ mouse intestine using ethylenediaminetetraacetic acid (EDTA). A total of 500 isolated crypts were mixed with $50 \mu \mathrm{L}$ of Matrigel (BD Bioscience, San Jose, CA, United States) and plated in 24-well plates. After matrigel polymerization, $500 \mu \mathrm{L}$ of IntestiCult Organoid Growth Medium (STEMCELL Technologies, Vancouver, Canada) was added on the top for organoid culture. Organoids were maintained at $37^{\circ} \mathrm{C}$ in a Forma incubator (Thermo Fisher Scientific, Waltham, MA, United States) containing 5\% CO2 and 95\% humidity. Organoids were treated with different concentrations of triptolide for $72 \mathrm{~h}$. ATP levels were measured using the Cell-Titer Glo2.0 Cell Viability Assay Kit (Promega, Madison, WI, United States) according to the manufacturer's instructions.

\section{Cell culture and treatment}

Colorectal cancer cells RKO and HCT116 were obtained from ATCC and cultured in DMEM medium supplemented with $10 \%$ fetal bovine serum (Thermo Fisher Scientific). Cells were maintained at $37^{\circ} \mathrm{C}$ in a Forma incubator (Thermo Fisher Scientific) containing 5\% $\mathrm{CO}_{2}$ 
and $95 \%$ humidity. Cells seeded in plates were treated with triptolide at the different concentration for the indicated time and then subjected to further experiments.

\section{CCK8-based viability assay}

The effect of Triptolide on cell viability was assessed by Cell Counting Kit-8 (CCK8) assay (Dojindo Laboratory, Japan). RKO cells or HCT116 cells were then treated with Triptolide for $48 \mathrm{~h} .10 \mu \mathrm{l}$ of CCK8 reagent was added to each well and the cells were incubated for $2 \mathrm{~h}$ at $37^{\circ} \mathrm{C}$. The optical density (OD) at $450 \mathrm{~nm}$ was measured by using VarioskanFlash (Thermo Scientific).

\section{Cell cycle analysis}

The effect of triptolide on cell cycle was assessed using propidium iodide staining and flow cytometry. RKO cells or HCT116 cells treated with or without triptolide at different concentrations for $24 \mathrm{~h}$ were fixed with $70 \%$ ice-cold ethanol for $12 \mathrm{~h}$, stained with propidium iodide ( $5 \mu \mathrm{M}$, BioVision, Inc.) for $30 \mathrm{~min}$ at room temperature and examined with a flow cytometer as mentioned before (Beckman Coulter, Brea, CA, United States). DNA histograms were analyzed.

\section{Colony formation assay}

To detect the effect of triptolide on colony formation, cells were seeded at a density of 500 cells/well in a 6-well plate and allowed to adhere for $24 \mathrm{~h}$. The cells were then treated with triptolide of $5,10 \mathrm{nM}$ or control DMSO (designated as $0 \mathrm{nM}$ ). After $24 \mathrm{~h}$, the medium was replaced with fresh medium and replaced again every 3 days thereafter. The cells were grown for 10 days, then fixed using methanol and stained with $1 \%$ crystal violet. Wells containing more than 50 cells were counted. The experiment was performed at least three times. The number of colonies in triptolide group was analyzed by comparing with DMSO control.

\section{RNA purification and reverse transcription reaction}

Total RNA was isolated with Trizol reagent (Life Technologies, Grand Island, NY, United States) following the manufacturer's protocol. $0.5 \mu \mathrm{g}$ of total RNA was reverse transcribed using random hexamers and the High Capacity cDNA Reverse Transcription Kit (Life Technologies).

\section{The real-time quantitative PCR analysis}

The real-time quantitative PCR analysis was performed in $10-\mu l$ reactions using SYBR GREEN PCR Master Mix (Applied Biosystems). The related mRNA level was normalized to the $\beta$-actin mRNA level. Data were analyzed using the $2^{-\Delta \Delta C t}$ method [19]. Sequences of all the primers used for PCR amplification are listed in Additional file 1: Table S1.

\section{Immunoblotting analysis}

Proteins were quantified by BCA protein assay kit (Beyotime Biotechnology, Shanghai, China) and applied to immunoblotting analysis as described previously [20]. $50 \mu \mathrm{g}$ of total proteins were subjected to sodium dodecyl sulfate polyacrylamide gel electrophoresis (SDS-PAGE) and transferred to nitrocellulose membrane (Whatman, Clifton, NJ, United States). Membrane was blocked with 3\% bovine serum albumin in TBS-T buffer $(20 \mathrm{mM}$ Tris- $\mathrm{HCl}, \mathrm{pH} 8.0,150 \mathrm{mM} \mathrm{NaCl}, 0.05 \%$ Tween- 20), probed with antibodies targeting to FLAG-tag (Cell Signaling Technology, Beverly, MA, United States), Myc-tag (Cell Signaling Technology), TBP (Cell Signaling Technology), POLR3D (Abcam, Cambridge, MA, United States), or ACTB (Cell Signaling Technology). The membrane was incubated with horseradish-conjugated secondary antibodies and visualized using enhanced chemiluminescence.

\section{Puromycin labeling}

Cells at $70-80 \%$ confluence were treated with $10 \mu \mathrm{g} / \mathrm{mL}$ puromycin for $10 \mathrm{~min}$. After washing with ice-cold PBS, cells were lysed and proteins were subjected to immunoblotting with puromycin antibody.

\section{Chromatin immunoprecipitation (ChIP)}

ChIP assays were performed using the ChIP assay kit (Thermo Fisher Scientific) following the manufacturer's protocol. Briefly, RKO cells transfected with FLAG-tagged proteins were cross-linked with $1 \%$ formaldehyde for $10 \mathrm{~min}$ at $37^{\circ} \mathrm{C}$. Cross-linking was stopped with $0.125 \mathrm{M}$ glycine. After sonication to yield DNA fragments of 300-1000 base pairs, the lysates were cleared by centrifugation, diluted 6 -fold with ChIP dilution buffer, and precleared with salmon sperm DNA/ protein A-agarose at $4{ }^{\circ} \mathrm{C}$ for $1 \mathrm{~h}$. For each immunoprecipitation assay, the lysates were incubated with $2 \mu \mathrm{g}$ of anti-FLAG (Sigma) or control IgGs (Santa Cruz Biotechnology) overnight at $4{ }^{\circ} \mathrm{C}$ with rotation. The immunocomplexes were then collected with protein A-agarose slurry, eluted, and de-crosslinked at $65^{\circ} \mathrm{C}$. After RNase digestion and proteinase digestion, immunoprecipitated DNA was extracted. The purified DNA was amplified by real-time PCR.

Sequences of the primers used for tRNA ${ }^{\text {Leu }}$ and $5 \mathrm{~S}$ rRNA promoter amplification are listed in Additional file 1: Table S1.

\section{Plasmids}

For the construction of FLAG-tagged Brf1, TBP, or POLR3D, the corresponding genes were amplified by PCR and cloned to the vector p3XFLAG-CMV-13 between HindIII and EcoRI sites. To construct myc-tagged Brf1, Brf1 gene was amplified and cloned to the vector pcDNA3.1-myc-his B between HindIII and EcoRI sites. 
TBP and POLR3D genes were cut by HindIII/KpnI from p3XFLAG-CMV-13 and subcloned to pEYFP-N1 to get YFP-tagged fusion genes. Brf1 gene was cut by HindIII/ KpnI from p3XFLAG-CMV-13 and subcloned to pECFP-N1 to get CFP-tagged fusion gene.

All the oligo sequences were listed in Additional file 1: Table S1.

\section{Co-immunoprecipitation (co-IP)}

Co-IP was carried to detect the effect of triptolide on the interactions between TFIIIB components. Briefly, the cells transfected with indicated plasmids expressing FLAG- or Myc-tagged proteins were lysed with RIPA buffer $(20 \mathrm{mM}$ Tris- $\mathrm{HCl}, \mathrm{pH} 7.5,150 \mathrm{mM} \mathrm{NaCl}, 1 \mathrm{mM}$ EDTA, 1\% NP-40) with freshly-added complete protease inhibitor cocktail (Roche Applied Science, Indianapolis, IN). Cell lysates were precipitated with FLAG beads (Sigma) at $4{ }^{\circ} \mathrm{C}$ overnight. After washing 3 times with lysis buffer, immunocomplexes were boiled directly in loading buffer and subjected to sodium dodecyl sulfate polyacrylamide gel electrophoresis (SDS-PAGE).

\section{Fluorescence resonance energy transfer (FRET)}

FRET analysis was carried out to detect the effect of triptolide on the interactions between TFIIIB components. FRET was performed as described previously [21]. Plasmids expressing yellow fluorescent protein (YFP)- and cyan fluorescent protein (CFP)- tagged proteins were transfected into RKO cells. Twenty-four hours after transfection, cells were examined with the VarioskanFlash (Thermo Fisher Scientific). The wavelength of 458 $\mathrm{nm}$ was used for excitation. An emission wavelength of 470-500 nm was used for CFP, and an emission wavelength of $520-550 \mathrm{~nm}$ was used for YFP. The ratio of YFP intensity/CFP intensity was used for calculating FRET efficiency. Data from 5 independent experiments were subjected to statistical analysis.

\section{Human samples}

To detect the expression of Pol III products in human CRC samples, 10 paired fresh CRC cancer, and adjacent non-cancer tissues were collected from the tissue bank of the Second Affiliated Hospital of Zhejiang University School of Medicine [22]. The details regarding the samples were disclosed in the Additional file 1: Table S2. A similar amount of starting material was used, including tissue weight, amount of RNA used for reverse transcription, etc. Ethics approval for these studies was obtained from the Ethics Committee of Zhejiang University School of Medicine (\#2018-021, 2018 updated) [22]. All procedures performed in this study involving human participants were in accordance with the 1964 Helsinki declaration and its later amendments or comparable ethical standards.
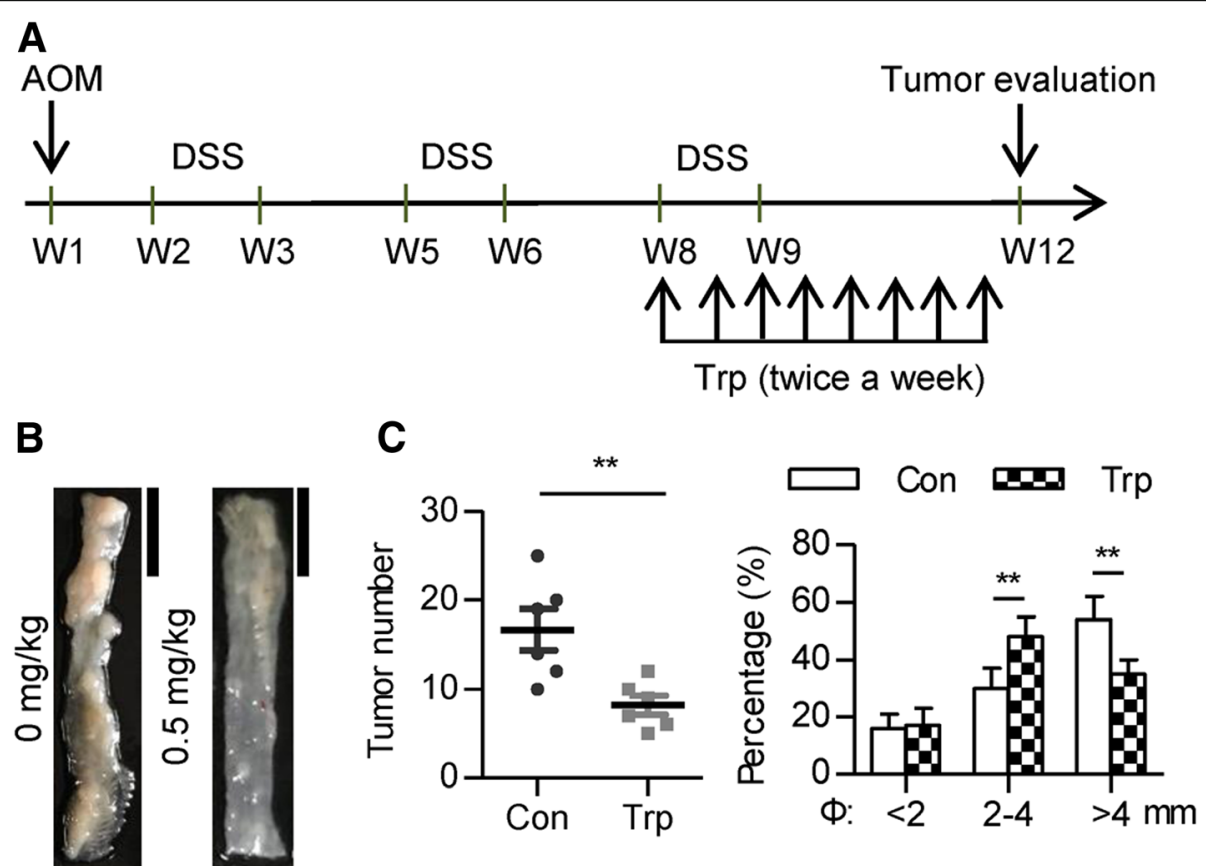

Fig. 1 Triptolide attenuates tumor development in AOM/DSS mice. a The workflow of the triptolide treatment in AOM/DSS-induced colitis-associated cancer (CAC) model. b Representative colons from control or triptolide-treated mice on day 80 of AOM/DSS induction. Scale bar: $1 \mathrm{~cm}$. c Colon tumor number and size distribution from control or triptolide-treated. ${ }^{*} P<0.01$ 


\section{Statistical analysis}

The experiments were repeated at least three times and data were presented as mean \pm SD. For the data following normal distribution, statistical significance between two groups was determined with the Student's $t$-test. Statistical significance among more than 3 groups was determined with one-way analysis of variance (ANOVA). For the CRC tissue samples that do not follow normal distribution, statistical significance between two groups was determined with the Mann-Whitney test. All comparisons were two-tailed and $P<0.05$ was considered significant.

\section{Results}

Triptolide attenuates cancer development in AOM/DSS mice

To evaluate the therapeutic effect of triptolide in the real context of colorectal cancer development, we firstly applied carcinogen (AOM/DSS)-induced mouse CRC model. Eight-week-old female C57BL/6 J mice were subjected to AOM/DSS induction. After tumor formation, mice were intraperitoneally administrated with either $0.5 \mathrm{mg} / \mathrm{kg}$ triptolide in DMSO or DMSO only (control group) twice a week (Fig. 1a). Consistent with the previous study [23], triptolide treatment at this concentration did not induce significant liver toxicity (Additional file 1: Figure S1). DSS water consumption was similar between the two groups. Triptolide treatment at this concentration did not change DSS-induced weight loss compared with the control group. Twelve weeks after tumor induction, the mice were euthanized and the colon was analyzed for tumor number and size. Data showed that triptolide treatment significantly decreased the total tumor burden (Fig. 1b, c). Moreover, the percentage of larger $(>4 \mathrm{~mm})$ tumors decreased while the percentage of middle size $(2-4 \mathrm{~mm})$ tumors increased in Trp group, indicating that triptolide decreases the size of AOM/ DSS-induced tumor (Fig. 1c).

\section{Triptolide inhibits tumorigenesis in $\mathrm{Apc}^{\mathrm{Min} /+}$ mice and represses organoid growth}

To further confirm the inhibitory effect of triptolide on colorectal cancer development, we used $\mathrm{Apc}^{\mathrm{Min} /+}$ mouse model, carrying a truncation mutation at the tumor suppressor gene $A p c$, which mainly induces adenoma formation in the small intestine. We treated 3-month-old $\mathrm{Apc}^{\mathrm{Min} /+}$ mice with triptolide for 3 months and evaluated tumor number and size (Fig. 2a). Weight gain was
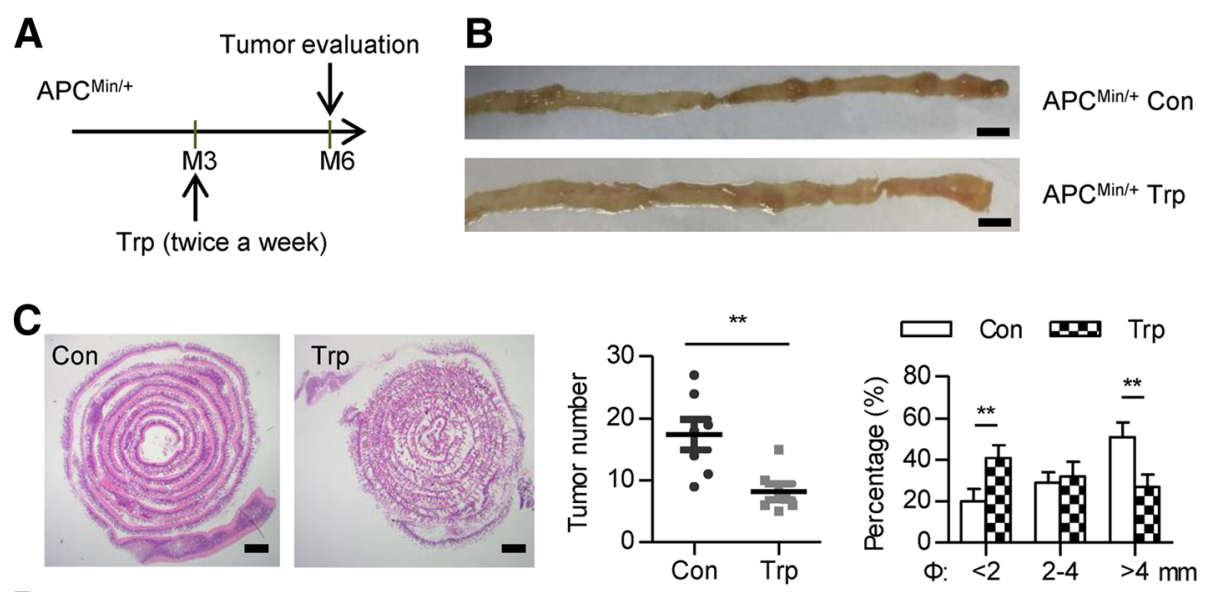

D
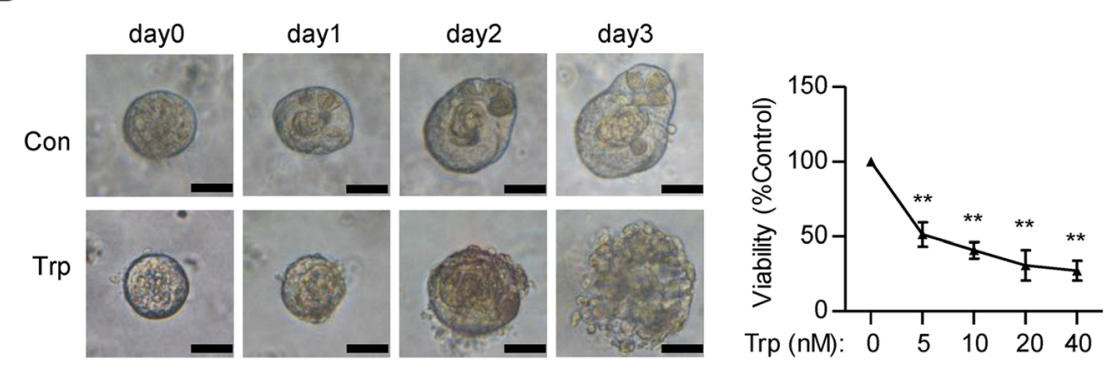

Fig. 2 Triptolide inhibits tumorigenesis in $\mathrm{ApC}^{\mathrm{Min} /+}$ mice and disrupts organoid growth. a The workflow of the triptolide treatment in the $\mathrm{Apc}^{\mathrm{Min} /+}$ mouse model. $\mathbf{b}$ The small intestines from 6-month-old Apc ${ }^{\mathrm{Min} /+}$ mice treated with or without triptolide for $3 \mathrm{months}$. Scale bar: $1 \mathrm{~cm}$. $\mathbf{c}$ H\&E staining of the small intestines from 6-month-old $\mathrm{Apc}^{\mathrm{Min} /+}$ mice treated with or without triptolide for 3 months. Scale bar: $1 \mathrm{~mm}$. Tumor number and size distribution from $\mathrm{Apc}^{\mathrm{Min} /+}$ mice treated with or without triptolide were analyzed. ${ }^{*} P<0.01$. $\mathbf{d}$ Organoids isolated from Apc ${ }^{\mathrm{Min} /+}$ mice were treated with or without $5 \mathrm{nM}$ of triptolide and pictures were taken under a microscope. Scale bar: $25 \mu \mathrm{m}$. Organoids were treated with different concentration of triptolide for $72 \mathrm{~h}$ and cell viability (ATP level) was measured. ${ }^{*} P<0.01$ 
comparable between groups. Triptolide treatment significantly reduced both tumor burden and tumor size (Fig. 2b, c). These results suggested that upon loss of APC, triptolide reduces tumor formation of small intestinal tumors.

Self-renewal of the intestinal epithelium is driven by Lgr5 stem cells located in crypts [24]. We, therefore, evaluated the effect of triptolide on the growth of organoids from $\mathrm{Apc}^{\mathrm{Min} /+}$ mice. Data showed that $72 \mathrm{~h}$ of triptolide treatment at the concentration of $5 \mathrm{nM}$ induced organoid disruption. We next quantified organoids viability through measurements of ATP levels. Data showed that triptolide reduces organoids viability in a dose-dependent manner (Fig. 2d).

\section{Triptolide inhibits colorectal cancer cell growth and induces apoptosis}

Further, we evaluated the effect of different doses of triptolide on the viability of colon cancer cells. Data showed that triptolide decreased the viability of both HCT116 and RKO colon cancer cells in a dose-dependent fashion (Fig. 3a). To identify the cellular events that inhibit RKO

\section{A}
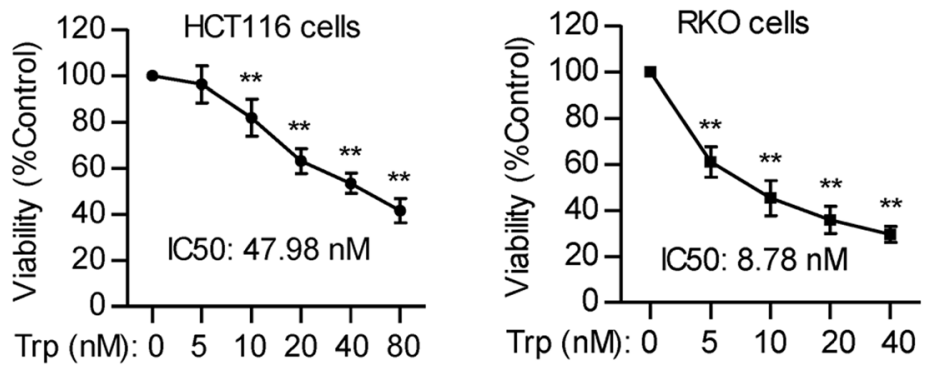

B
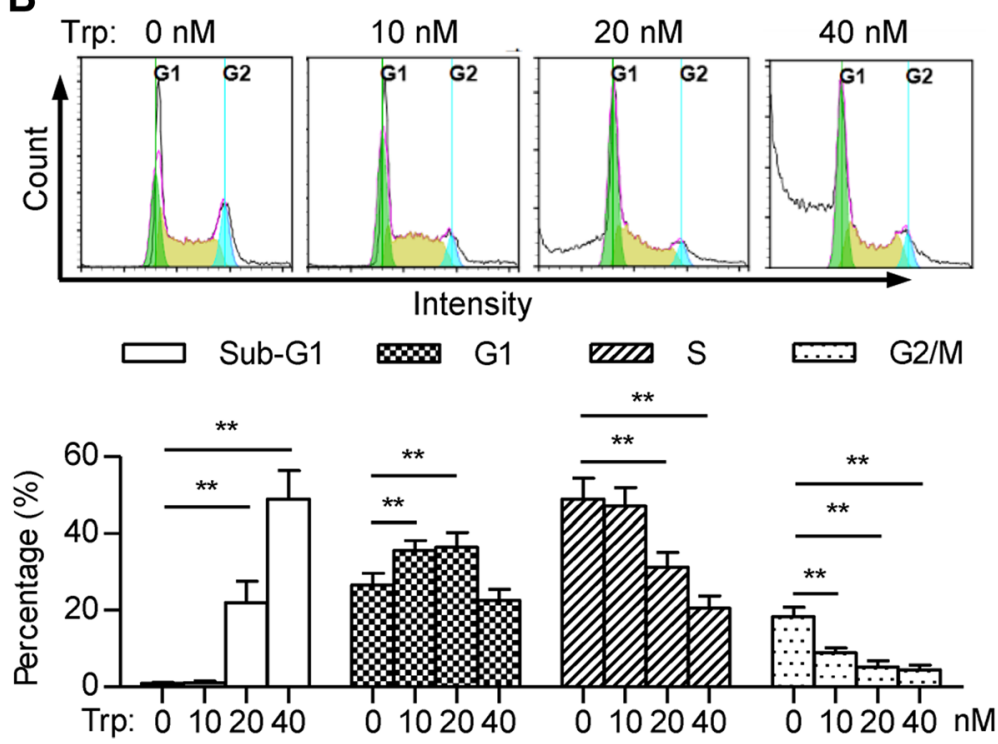

C
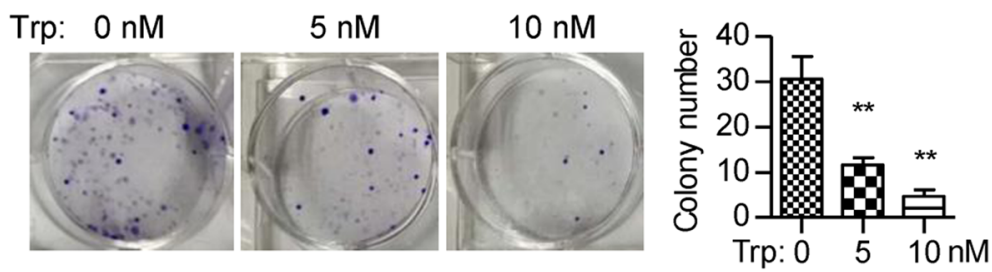

Fig. 3 Triptolide inhibits colorectal cancer cell growth and induces apoptosis. a HCT116 and RKO cells were incubated with triptolide at different concentrations for $48 \mathrm{~h}$, and cell viability was determined using cell counting kit-8 (CCK-8). ${ }^{* *} P<0.01$. b RKO cells were incubated with triptolide at different concentrations for $24 \mathrm{~h}$ and the cell cycle was determined. Cell percentage at G0/G1, S, G2, and sub-G1 phases was calculated and analyzed. c Colony formation assay in RKO cells treated with different concentration of triptolide. All the data are presented as the mean \pm SD of at least three independent experiments. ${ }^{*} P<0.05,{ }^{*} P<0.01$ 
cell proliferation, we used propidium iodide staining to analyze cell cycle. Data showed that a lower concentration of triptolide $(10 \mathrm{nM})$ treatment induced cells accumulation at G0/G1 cycle, while a higher concentration of triptolide $(>20 \mathrm{nM})$ increased the sub-G1 population, which are apoptotic cells (Fig. 3b). Triptolide mainly induced G2 cycle arrest and cell apoptosis in HCT116 cells (Additional file 1: Figure S2). In addition, triptolide treatment significantly decreased colony formation of RKO cells (Fig. 3c).

\section{Triptolide inhibits pol III transcription}

Triptolide could inhibit both Pol I and Pol II transcription. Pol III products, including tRNAs, 5S rRNA, control mRNA translation efficiency and growth capacity of cells $[14,15]$. We hypothesize that triptolide also inhibits Pol III transcription. To our surprise, $40 \mathrm{nM}$ of triptolide treatment for only $0.5 \mathrm{~h}$ dramatically reduced the expression of Pol III products including 5S rRNA, pre-tRNA ${ }^{\text {Leu, }}$ pre-tRNA ${ }^{\mathrm{Tyr}}$, and 7SL RNA. The expression level of these genes further decreased with time extends (Fig. 4a). Triptolide inhibited Pol III transcription in a dose-dependent manner, and the inhibitory effect could be observed at the concentration of $2.5 \mathrm{nM}$ (Fig. 4b). The inhibition of triptolide on Pol III was also observed in HCT116 cells (Additional file 1: Figure S3). Moreover, tumors from triptolide-treated AOM/DSS mouse showed reduced Pol III transcription compared with the control group, confirming the inhibitory effect of triptolide on Pol III transcription (Fig. 4c).

\section{Triptolide inhibits mRNA translation efficiency}

To detect whether reduced Pol III transcription affects mRNA translation efficiency, we performed polysome profiling. $1 \mathrm{~h}$ of triptolide treatment at the concentration of $40 \mathrm{nM}$ slightly reduced the polysome/monosome (P/M) ratio, while $4 \mathrm{~h}$ of triptolide treatment dramatically decreased $\mathrm{P} / \mathrm{M}$ ratio, indicating the reduced translation efficiency (Fig. 5a, b, c). As an independent validation, we examined the synthesis of endogenous proteins using puromycin labeling [25]. In agreement with polysome profiling, the total levels of puromycin-labeled nascent chains were significantly decreased after $4 \mathrm{~h}$ of triptolide treatment (Fig. 5d).

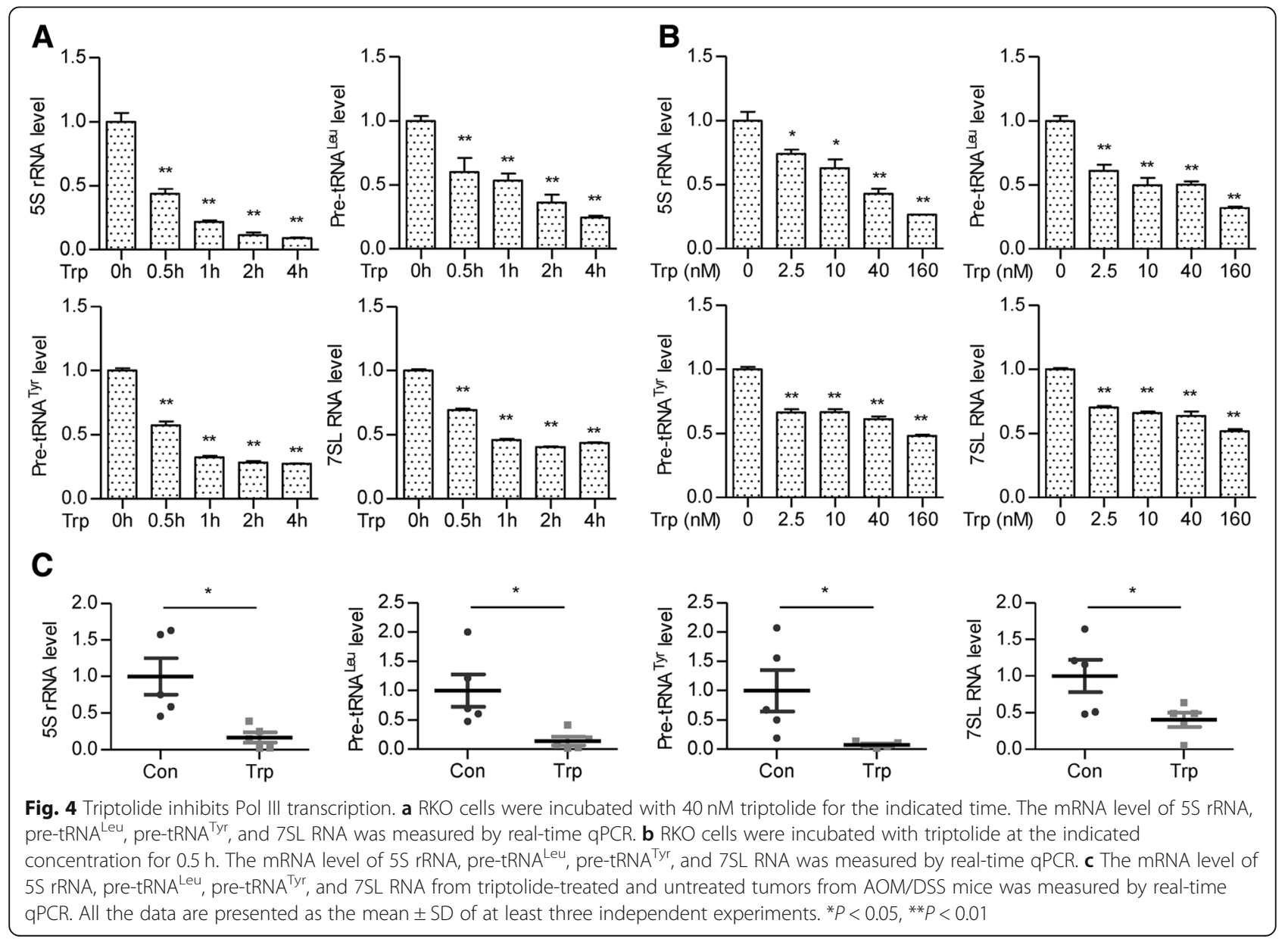



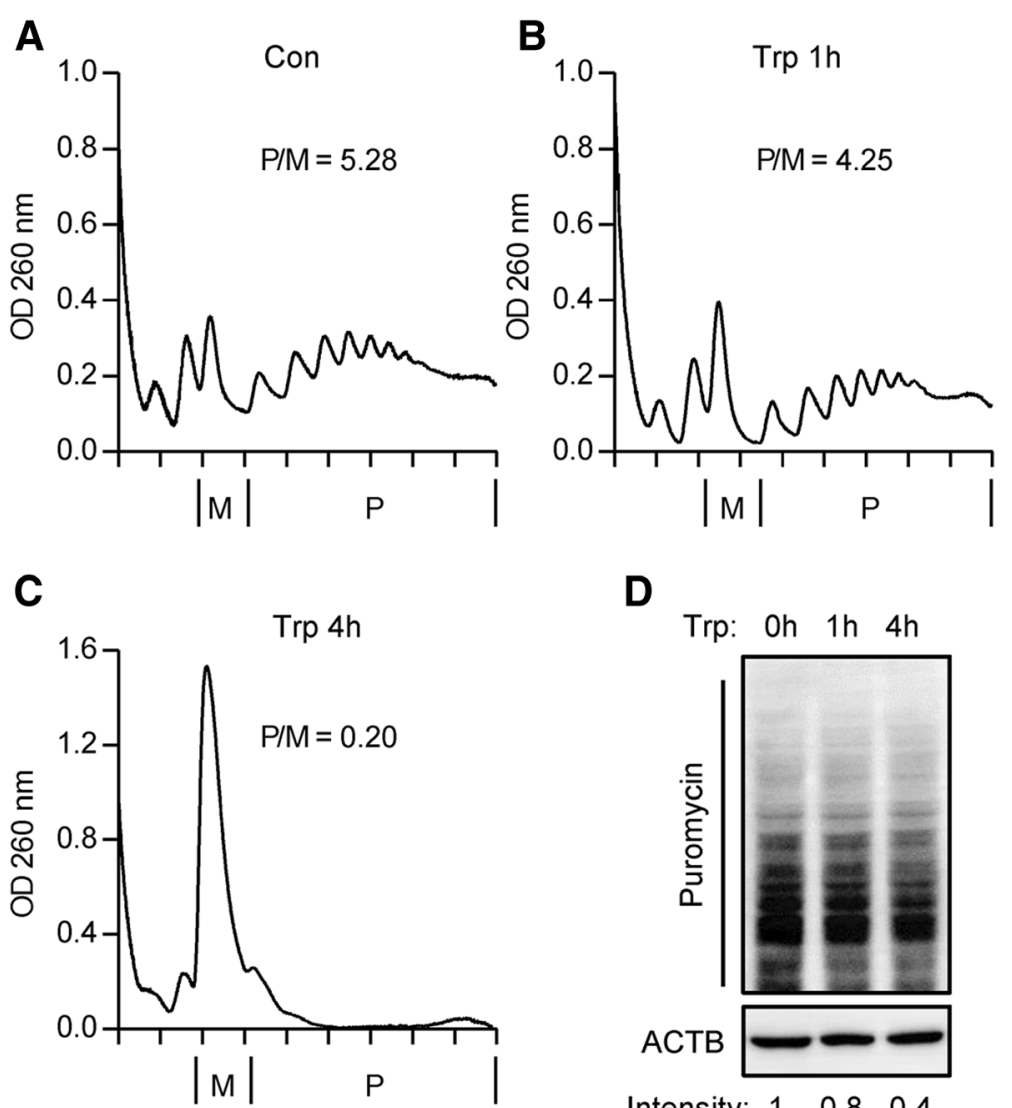

D

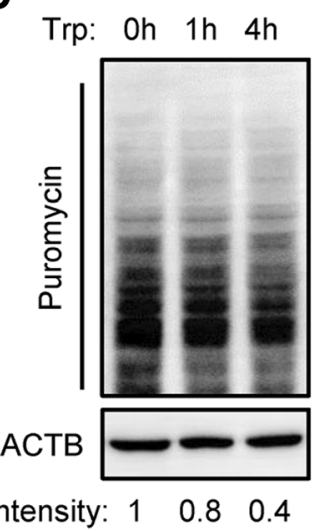

Fig. 5 Triptolide inhibits mRNA translation efficiency. a, b, c RKO cells were treated with $40 \mathrm{nM}$ triptolide for the indicated time. Polysome profiling was carried out. $\mathbf{d}$ RKO cells were treated with $40 \mathrm{nM}$ triptolide for the indicated time and the newly synthesized peptides were detected by puromycin labeling

Triptolide disrupts TFIIIB formation at pol III promoters The principal transcription initiation factor of Pol III is TFIIIB, a complex consisting of TBP, Brf1, and Bdp1. To explore the potential mechanism of reduced Pol III transcription, we detected the expression of TBP, Brf1, Bdp1, and POLR3D, one subunit of Pol III. We observed reduced expression of these genes after $2 \mathrm{~h}$ of triptolide treatment, which is later than decreased Pol III products. $0.5 \mathrm{~h}$ of triptolide treatment did not affect the expression level of these genes even at very high concentration (160 nM) (Fig. 6a, b). Therefore, triptolide-inhibited Pol III transcription was not due to the decreased expression of Pol III machinery.

During the initiation of Pol III transcription, TBP mediates the binding of TFIIIB with promoter DNA, while Brf1 holds together the trimeric TBP-Brf1-Bdp1 complex. Thereafter, Brf1 and Bdp1 work together to recruit Pol III to form a transcriptionally active preinitiation complex (PIC) [26, 27]. To determine the effect of triptolide on PIC formation, we labeled each subunit with the FLAG tag and performed ChIP experiments. Data showed that $0.5 \mathrm{~h}$ of triptolide treatment reduced the recruitment of POLR3D at promoters of $5 \mathrm{~S}$ rRNA and

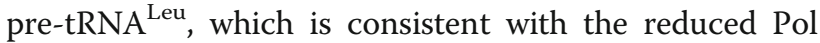
III transcription. Triptolide did not affect the binding of TBP with the promoter DNA, but significantly reduced the recruitment of Brf1 (Fig. 6c), suggesting the repressed TFIIIB formation at these promoters.

\section{Triptolide blocks the interaction between TBP and Brf1}

Data above prompted us to detect the interaction between TFIIIB components after triptolide treatment. We first carried out the Co-IP experiments. In agreement with the ChIP results, triptolide reduced the binding of TBP with Brf1 and POLR3D. However, triptolide treatment did not affect the interaction between Brf1 and POLR3D (Fig. 7a, b). These data indicated that triptolide targets TBP/Brf1 binding. As a negative control, FLAG-tagged GFP did not interact with either TBP or POLR3D (Fig. 7c).

To further confirm the Co-IP results, we performed FRET analysis. CFP-tagged Brf1 and YFP-tagged TBP were excited with the appropriate laser line $(458 \mathrm{~nm}$ for CFP or $514 \mathrm{~nm}$ for YFP). Emission spectra scanning demonstrated that the emission Brf1-CFP and TBP-YFP peaks at about $475 \mathrm{~nm}$ and $525 \mathrm{~nm}$ respectively. Cells expressing both Brf1-CFP and TBP-YFP were excited at 458 

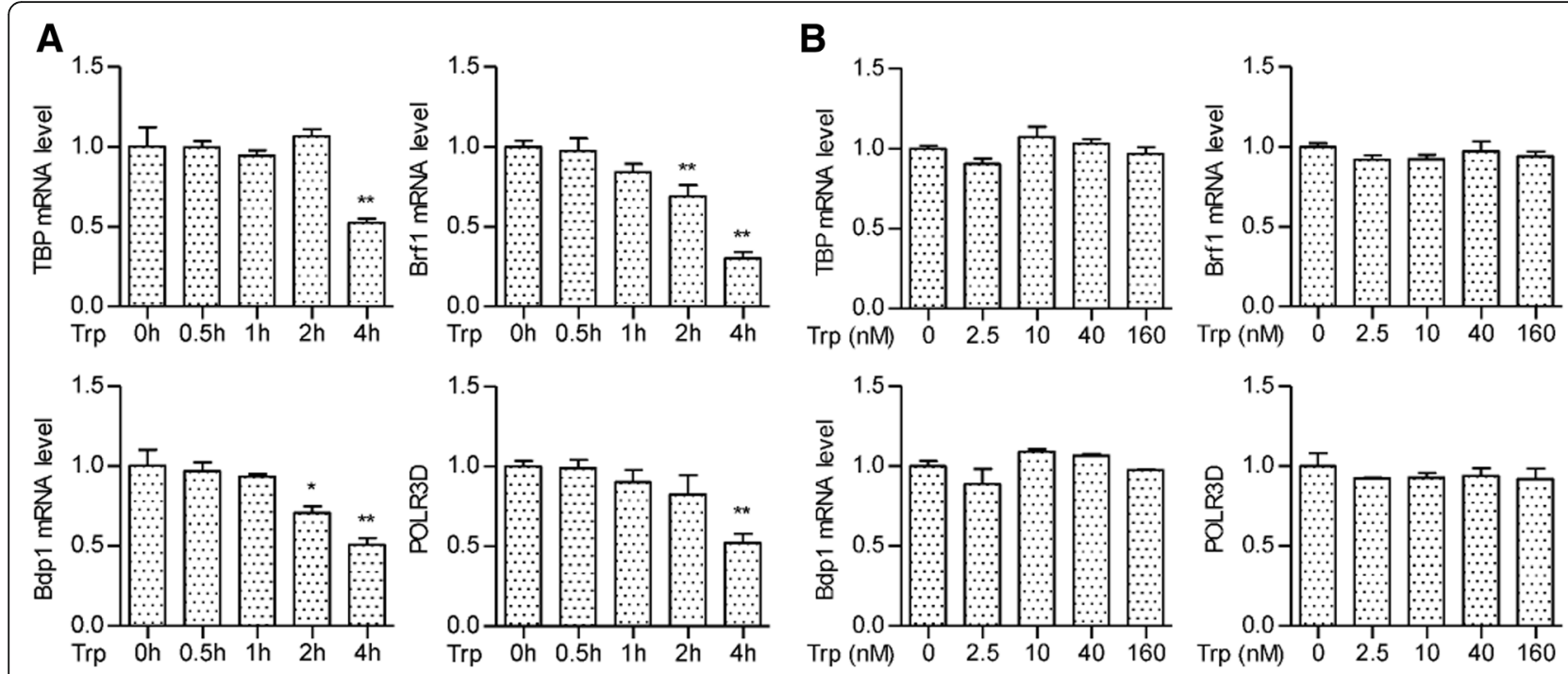

C

$5 S$ rRNA promoter

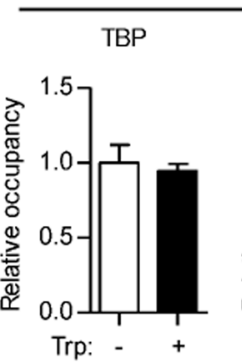

$\operatorname{Brf} 1$

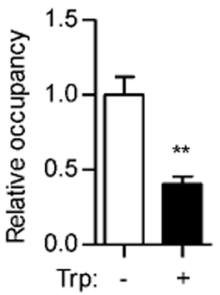

POLR3D

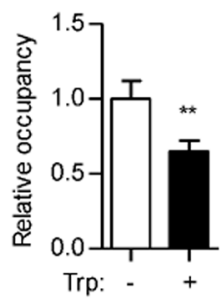

tRNA ${ }^{\text {Leu }}$ promoter

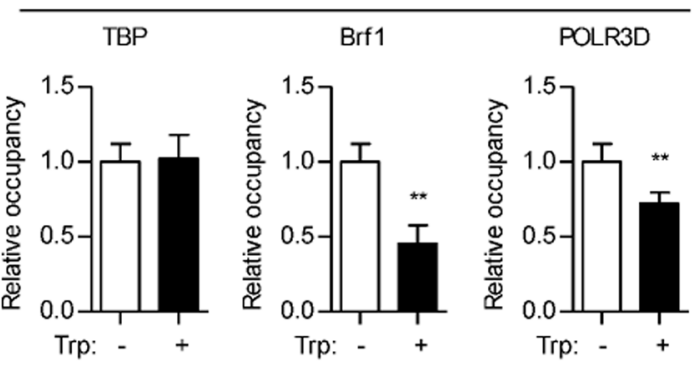

Fig. 6 Triptolide represses TFIIIB formation at Pol III promoters. a RKO cells were incubated with $40 \mathrm{nM}$ triptolide for the indicated time. The mRNA level of TBP, Brf1, Bdp1, and POLR3D was measured by real-time qPCR. $\mathbf{b}$ RKO cells were incubated with triptolide at the indicated concentration for $0.5 \mathrm{~h}$. The mRNA level of TBP, Brf1, Bdp1, and POLR3D was measured by real-time GPCR. $\mathbf{c}$ RKO cells expressing FLAG-tagged TBP, Brf1, or POLR3D were treated with or without $40 \mathrm{nM}$ triptolide for $0.5 \mathrm{~h}$. Chromatin immunoprecipitation was carried out using FLAG antibody and the immunoprecipitates were subjected to qPCR

$\mathrm{nm}$ to detect if there is FRET between these two proteins. We observed a decrease in the CFP emission and an increase in the YFP emission, demonstrating that FRET did happen between Brf1-CFP and TBP-YFP. FRET was detected in Brf1-CFP/POLR3D-YFP, but neither in CFP/ TBP-YFP nor in CFP/POLR3D-YFP (Fig. 7d).

Taken advantage of YFP/CFP intensity ratio reflecting $\mathrm{TBP} / \mathrm{Brf1}$ interaction, we detected the interaction between $\mathrm{TBP} / \mathrm{Brf1}$ real-timely after adding triptolide to the medium. The YFP/CFP ratio decreased significantly 30 min after triptolide addition, demonstrating the disruption of TBP/Brf1 binding (Fig. 7e). In line with Co-IP results, triptolide did not affect FRET efficiency between Brf1CFP and POLR3D-YFP (Fig. 7e).

\section{Pol III products are upregulated in CRC}

Given that triptolide targets Pol III in cultured cancer cells and animal intestinal cancer model, we continued to investigate the relationship between Pol III transcription and CRC. We examined Pol III products, including $5 \mathrm{~S}$
rRNA, pre-tRNA ${ }^{\mathrm{Leu}}$, pre-tRNA ${ }^{\mathrm{Tyr}}$, and 7SL RNA in 10 paired CRC patient samples. RT-qPCR measurement revealed that the expression of $5 \mathrm{~S}$ rRNA, pre-tRNA ${ }^{\text {Leu }}$, pre-tRNA ${ }^{\text {Tyr }}$ was significantly increased in CRC tissues comparing to the adjacent non-cancer ones (Fig. 8), implying an oncogenic activity of Pol III products in CRC development.

\section{Discussion}

In the current study, we demonstrate that triptolide, a diterpene triepoxide from a Chinese herb Trypterigium wilfordii, inhibits colorectal carcinogenesis in both $\mathrm{Apc}^{\mathrm{Min} /+}$ and AOM/DSS mouse models. Our study strongly indicates that triptolide and triptolide-like drugs are promising colorectal cancer therapies. Importantly, we demonstrate that triptolide inhibits Pol III-dependent 5S rRNA and tRNAs transcription. To our knowledge, this is the first report demonstrating that triptolide inhibits Pol III transcription. 


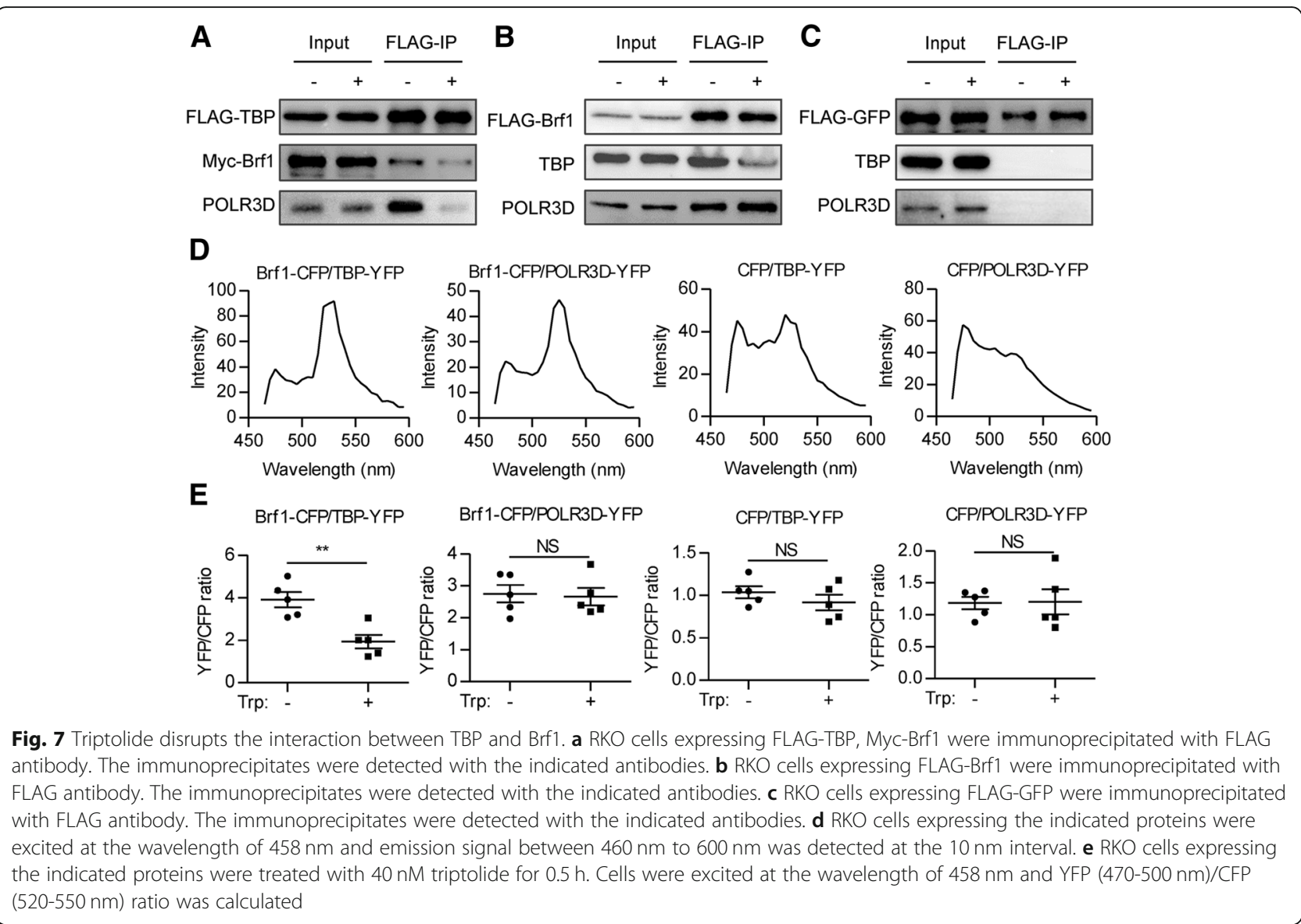

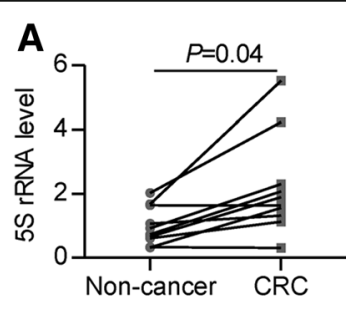

C

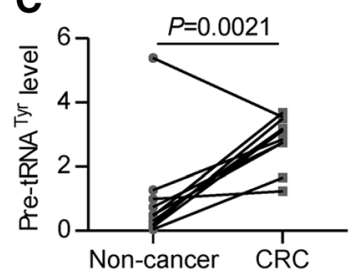

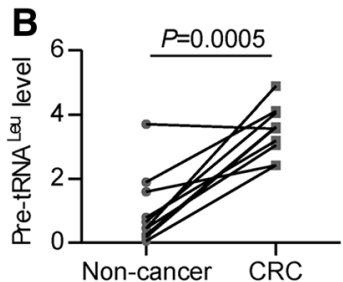

D

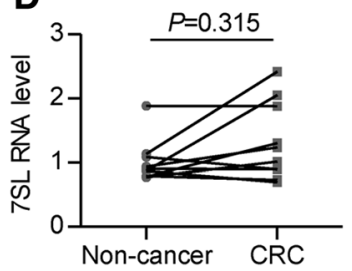

E

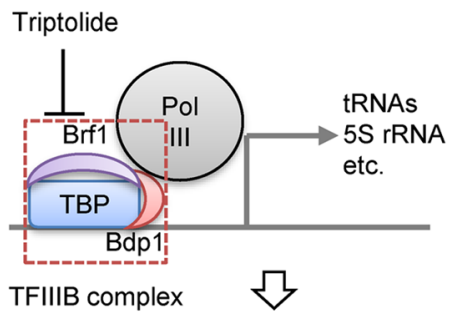

mRNA translation

\& cancer cell growth

Fig. 8 Pol III products are upregulated in CRC. $\mathbf{a}, \mathbf{b}, \mathbf{c}, \mathbf{d}$ The expression of 5 S rRNA (a), pre-tRNA ${ }^{\text {Leu }}$ (b), pre-tRNA ${ }^{\text {Tyr }}$ (c), and 7SL RNA (d) from CRC tissues or adjacent non-cancer tissues was measured by real-time GPCR. The expression level was calculated as fold change with ACTB as endogenous control and normalized to the mean of non-cancerous group values. Dots indicate individual values. (e) The working model for triptolide-inhibited Pol III transcription and cancer cell growth 
Triptolide has been shown to be effective against colon cancer cell growth [28]. However, most of these studies are based on in vitro cell models or xenograft models, which do not reflect the real context of colorectal cancer tumorigenesis. Our study, for the first time, demonstrated the anticancer effect of triptolide on colorectal cancer formation in both $\mathrm{Apc}^{\mathrm{Min} /+}$ and AOM/DSS mice. Moreover, using cultured 3D organoids, we demonstrated that triptolide at nanomolar concentration could inhibit organoid growth from $\mathrm{Apc}^{\mathrm{Min} /+}$ mouse. Since the growth of $\mathrm{Apc}^{\mathrm{Min} /+}$ organoids reflects the self-renewal activity of intestinal stem cells, our data suggested a role of triptolide in inhibiting colorectal cancer stem cell function. Of note, our data showed that triptolide can also inhibit the growth of normal intestinal organoids at higher concentration compared with the organoids from $\mathrm{Apc}^{\mathrm{Min} /+}$ mice (Additional file 1: Figure S4). We proposed that, like most of the chemical drugs, triptolide does not have cell type selectivity. However, the cancer cells have a higher level of Pol III transcription, making them more sensitive to triptolide treatment.

Although the precise molecular targets remain elusive, recent studies in cancer cells have revealed that RNA polymerase may be an important target of triptolide. McCallum et al. showed that triptolide inhibits de novo total RNA transcription [9]. Numerous evidence has demonstrated that triptolide inhibits Pol II transcription initiation $[10,11,29]$. In addition, triptolide could inhibit Wnt signaling in non-small cell lung carcinoma via epigenetic modifications to histone $\mathrm{H} 3$, indicating an inhibitory effect of triptolide on Pol II expression at the epigenetic level [30]. Leuenroth and Crews demonstrated that triptolide induced disappearance of normal nucleolar structure [12], which accounts for the reduced RNA Pol I transcription and subsequent ribosome biogenesis. The Pol III products including tRNAs and $5 \mathrm{~S}$ rRNA are translation machinery, which controls mRNA translation efficiency $[14,15]$. Therefore, it is reasonable to propose that Pol III transcription should be inhibited to coordinate with reduced Pol I and Pol II transcription. Indeed, triptolide treatment reduced the expression level of 5S rRNA and tRNAs in cultured colorectal cancer cells as well as in mouse colorectal cancer tissue. Accordingly, mRNA translation efficiency was dramatically inhibited after triptolide treatment. Interestingly, our results showed that $0.5 \mathrm{~h}$ of triptolide treatment did not affect the expression of TFIIIB components but blocked the formation of TFIIIB, suggesting a direct effect of triptolide on Pol III transcription machinery other than the side effect from Pol II inhibition. We observed that a long time of triptolide treatment inhibited the expression of TFIIIB components due to the inhibition of Pol II. Therefore, triptolide might inhibit Pol III transcription through both direct and indirect mechanisms.
TFIIIB plays an important role in recruiting Pol III to its target genes, making it an ideal target for regulation. By targeting TFIIIB, oncogenic proteins such as Ras, c-Jun, and c-Myc stimulate RNA Pol III transcription [31, 32], whereas tumor suppressors such as $\mathrm{pRb}, \mathrm{p} 53$, PTEN, and Maf1 repress Pol III transcription [14, 32]. The formation of TFIIIB complex at the promoter region requires multiple contacts between components of the basal transcription apparatus. First, TBP is recruited to the promoter of Pol III genes. Then, Brf1 and Bdp1 join to form TFIIIB complex at the class III gene promoters. After that, TFIIIB could recruit Pol III and initiate transcription. Our ChIP experiments showed that the loading of TBP to the promoter of 5S rRNA and tRNAs did not change under $0.5 \mathrm{~h}$ of triptolide treatment, while the loading of Brf1 and POLR3D was repressed (Fig. 6c). Co-IP and FRET experiments demonstrated that triptolide blocks TBP/Brf1 interaction without affecting Brf1/POLR3D interaction (Fig. 7). Based on these findings, we proposed a model that triptolide directly disrupts TFIIIB formation to inhibit Pol III transcription (Fig. 8e). Since most of Pol III products are the essential components of translation machinery, Pol III transcription is upregulated (Fig. 8) in cancer cells to satisfy the increased anabolic demands associated with cell growth. Due to its inhibitory effect on Pol III transcription, we envision that triptolide might serve as an effective drug candidate for CRC therapy.

\section{Conclusions}

In conclusion, besides inhibiting the transcription of Pol II and Pol I, triptolide also inhibits Pol III transcription by disrupting TFIIIB formation, leading to the suppression of mRNA translation (Fig. 8). The capability of triptolide to induce colorectal cancer cell growth arrest both in vitro and in vivo makes it a potential therapeutic drug candidate for CRC.

\section{Additional file}

Additional file 1: Table S1 Primers used in this study. Table S2 Details of the CRC samples used in this study. Figure $\mathbf{S} 1$ The effect of triptolide on liver function. Figure S2 Triptolide induces G2 cycle arrest and apoptosis in HCT116 cells. Figure S3 Triptolide inhibits Pol III transcription in HCT116 cells. Figure S4 The effect of triptolide on the growth of normal organoids. (DOCX $336 \mathrm{~kb})$

\section{Abbreviations}

AOM: Azoxymethane; Apc: Adenomatous polyposis coli; Bdp1: B double prime 1; Brf1: B-related factor 1; CAC: Colitis-associated cancer; CFP: Cyan fluorescent protein; ChIP: Chromatin immunoprecipitation; Co-IP: Coimmunoprecipitation; CRC: Colorectal cancer; DMSO: Dimethyl sulfoxide; DSS: Dextran sodium sulfate; EDTA: Ethylenediaminetetraacetic acid; FRET: Fluorescence resonance energy transfer; PCR: Polymerase chain reaction; Pol III: RNA polymerase III; SDS-PAGE: Sodium dodecyl sulfate polyacrylamide gel electrophoresis; TBP: TATA box-binding protein; YFP: Yellow fluorescent protein 


\section{Acknowledgments}

None.

\section{Funding}

This work was supported by grants from National Natural Science Foundation of China (81672847 to X.G.), and Zhejiang Provincial Natural Science Foundation of China (Grant No. LQ19C050004 to S.W., and LY16H040008 to X.S.). The work was also supported by the Sanming Project of Medicine in Shenzhen (SZSM201406007, SZSM201606088).

\section{Availability of data and materials}

All data generated or analyzed during this study are included in this published article.

\section{Authors' contributions}

ZL. and XG. designed the experiments. XL., RX., JS., BY., SW., RB., ZL., and ZC. performed the experiments. ZL., XG., ZC., RX., and JS. analyzed the data. XG. drafted the manuscript. All authors read and approved the final manuscript.

\section{Ethics approval and consent to participate}

Ten paired fresh CRC cancer and adjacent non-cancer tissues were collected from the tissue bank of the Second Affiliated Hospital of Zhejiang University School of Medicine. Ethics approval for these studies was obtained from the Ethics Committee of Zhejiang University School of Medicine.

All animal studies were performed in compliance with the Guide for the Care and Use of Laboratory Animals by the Medical Experimental Animal Care Commission of Zhejiang University. All animal studies used the protocol that has been approved by the Medical Experimental Animal Care Commission of Zhejiang University.

\section{Consent for publication}

Not application.

\section{Competing interests}

The authors declared no conflicts of interest.

\section{Publisher's Note}

Springer Nature remains neutral with regard to jurisdictional claims in published maps and institutional affiliations.

\section{Author details}

${ }^{1}$ Medical Research Institute, \& Guangdong Women and Children's Disease Precision Diagnosis and Treatment Engineering Technology Research Center, Baoan Maternal and Child Health Hospital, Jinan University, Shenzhen 518102, China. ${ }^{2}$ Department of Public Health, Zhejiang University School of Medicine, Hangzhou 310058, China. ${ }^{3}$ Sir Run-Run Shaw Hospital, Zhejiang University School of Medicine, Hangzhou 310058, China. ${ }^{4}$ Affiliated Central People's Hospital of Zhanjiang, Guangdong Medical University, Zhanjiang 524045, China.

\section{Received: 1 April 2019 Accepted: 15 May 2019}

\section{Published online: 23 May 2019}

\section{References}

1. Siegel RL, Miller KD, Jemal A. Cancer statistics, 2019. CA Cancer J Clin. 2019; 69(1):7-34.

2. Sobrero A, Kerr D, Glimelius B, Van Cutsem E, Milano G, Pritchard DM, Rougier P, Aapro M. New directions in the treatment of colorectal cancer: a look to the future. Eur J Cancer. 2000;36(5):559-66.

3. Zheng L, Jia J, Dai H, Wan L, Liu J, Hu L, Zhou M, Qiu M, Chen X, Chang L, Kim JY, Reckamp K, et al. Triptolide-assisted phosphorylation of p53 suppresses inflammation-induced NF-kappaB survival pathways in Cancer cells. Mol Cell Biol. 2017;37(15).

4. Wang Z, Jin H, Xu R, Mei Q, Fan D. Triptolide downregulates Rac1 and the JAK/STAT3 pathway and inhibits colitis-related colon cancer progression. Exp Mol Med. 2009;41(10):717-27.

5. Oliveira A, Beyer G, Chugh R, Skube SJ, Majumder K, Banerjee S, Sangwan V, Li L, Dawra R, Subramanian S, Saluja A, Dudeja V. Triptolide abrogates growth of colon cancer and induces cell cycle arrest by inhibiting transcriptional activation of E2F. Lab Investig. 2015;95(6):648-59.
6. Moser AR, Pitot HC, Dove WF. A dominant mutation that predisposes to multiple intestinal neoplasia in the mouse. Science. 1990;247(4940):322-4.

7. Neufert C, Becker C, Neurath MF. An inducible mouse model of colon carcinogenesis for the analysis of sporadic and inflammation-driven tumor progression. Nat Protoc. 2007;2(8):1998-2004.

8. Tanaka $T$, Kohno $H$, Suzuki $R$, Yamada $Y$, Sugie $S$, Mori $H$. A novel inflammation-related mouse colon carcinogenesis model induced by azoxymethane and dextran sodium sulfate. Cancer Sci. 2003;94(11): 965-73.

9. Vispe S, DeVries L, Creancier L, Besse J, Breand S, Hobson DJ, Svejstrup JQ, Annereau JP, Cussac D, Dumontet C, Guilbaud N, Barret JM, et al. Triptolide is an inhibitor of RNA polymerase I and II-dependent transcription leading predominantly to down-regulation of short-lived mRNA. Mol Cancer Ther. 2009;8(10):2780-90.

10. Titov DV, Gilman B, He QL, Bhat S, Low WK, Dang Y, Smeaton M, Demain AL, Miller PS, Kugel JF, Goodrich JA, Liu JO. XPB, a subunit of TFIIH, is a target of the natural product triptolide. Nat Chem Biol. 2011;7(3):182-8.

11. Manzo SG, Zhou ZL, Wang YQ, Marinello J, He JX, Li YC, Ding J, Capranico G, Miao ZH. Natural product triptolide mediates cancer cell death by triggering CDK7-dependent degradation of RNA polymerase II. Cancer Res. 2012;72(20):5363-73.

12. Leuenroth SJ, Crews CM. Triptolide-induced transcriptional arrest is associated with changes in nuclear substructure. Cancer Res. 2008;68(13):5257-66.

13. Dieci G, Fiorino G, Castelnuovo M, Teichmann M, Pagano A. The expanding RNA polymerase III transcriptome. Trends Genet. 2007;23(12):614-22.

14. White RJ. RNA polymerase III transcription and cancer. Oncogene. 2004; 23(18):3208-16.

15. Goodfellow SJ, Innes F, Derblay LE, MacLellan WR, Scott PH, White RJ. Regulation of RNA polymerase III transcription during hypertrophic growth. EMBO J. 2006;25(7):1522-33.

16. Graczyk D, Ciesla M, Boguta M. Regulation of tRNA synthesis by the general transcription factors of RNA polymerase III - TFIIIB and TFIIIC, and by the MAF1 protein. Biochim Biophys Acta. 2018;1861(4):320-9.

17. Winter AG, Sourvinos G, Allison SJ, Tosh K, Scott PH, Spandidos DA. White RJ. RNA polymerase III transcription factor TFIIIC2 is overexpressed in ovarian tumors. Proc Natl Acad Sci U S A. 2000;97(23):12619-24.

18. Johnson SA, Dubeau L, Johnson DL. Enhanced RNA polymerase IIIdependent transcription is required for oncogenic transformation. J Biol Chem. 2008;283(28):19184-91.

19. Livak KJ, Schmittgen TD. Analysis of relative gene expression data using real-time quantitative PCR and the 2(-Delta Delta C(T)) method. Methods. 2001;25(4):402-8.

20. Gao X, Dong H, Lin C, Sheng J, Zhang F, Su J, Xu Z. Reduction of AUF1mediated follistatin mRNA decay during glucose starvation protects cells from apoptosis. Nucleic Acids Res. 2014;42(16):10720-30.

21. Gao X, Hu H, Zhu J, Xu Z. Identification and characterization of follistatin as a novel angiogenin-binding protein. FEBS Lett. 2007;581(28):5505-10.

22. Bai R, Weng C, Dong H, Li S, Chen G, Xu Z. MicroRNA-409-3p suppresses colorectal cancer invasion and metastasis partly by targeting GAB1 expression. Int J Cancer. 2015;137(10):2310-22.

23. Yuan Z, Zhang H, Hasnat M, Ding J, Chen X, Liang P, Sun L, Zhang L, Jiang Z. A new perspective of triptolide-associated hepatotoxicity: liver hypersensitivity upon LPS stimulation. Toxicology. 2019:41445-56.

24. Sato T, Vries RG, Snippert HJ, van de Wetering M, Barker N, Stange DE, van Es JH, Abo A, Kujala P, Peters PJ, Clevers H. Single Lgr 5 stem cells build crypt-villus structures in vitro without a mesenchymal niche. Nature. 2009; 459(7244):262-5.

25. David A, Dolan BP, Hickman HD, Knowlton JJ, Clavarino G, Pierre P, Bennink $J R$, Yewdell JW. Nuclear translation visualized by ribosome-bound nascent chain puromycylation. J Cell Biol. 2012;197(1):45-57.

26. Vorlander MK, Khatter H, Wetzel R, Hagen WJH, Muller CW. Molecular mechanism of promoter opening by RNA polymerase III. Nature. 2018; 553(7688):295-300.

27. Abascal-Palacios G, Ramsay EP, Beuron F, Morris E, Vannini A. Structural basis of RNA polymerase III transcription initiation. Nature. 2018;553(7688):301-6.

28. Pan J. RNA polymerase - an important molecular target of triptolide in cancer cells. Cancer Lett. 2010;292(2):149-52.

29. Li SG, Shi QW, Yuan LY, Qin LP, Wang Y, Miao YQ, Chen Z, Ling CQ, Qin WX C-Myc-dependent repression of two oncogenic miRNA clusters contributes to triptolide-induced cell death in hepatocellular carcinoma cells. J Exp Clin Cancer Res. 2018;37(1):51. 
30. Nardi I, Reno T, Yun X, Sztain T, Wang J, Dai H, Zheng L, Shen B, Kim J, Raz

D. Triptolide inhibits Wnt signaling in NSCLC through upregulation of multiple Wnt inhibitory factors via epigenetic modifications to histone $\mathrm{H} 3$. Int J Cancer. 2018;143(10):2470-8.

31. Zhong S, Zhang C, Johnson DL. Epidermal growth factor enhances cellular TATA binding protein levels and induces RNA polymerase I- and IIIdependent gene activity. Mol Cell Biol. 2004;24(12):5119-29.

32. Johnson DL, Johnson SA. Cell biology. RNA metabolism and oncogenesis. Science. 2008;320(5875):461-2.

Ready to submit your research? Choose BMC and benefit from:

- fast, convenient online submission

- thorough peer review by experienced researchers in your field

- rapid publication on acceptance

- support for research data, including large and complex data types

- gold Open Access which fosters wider collaboration and increased citations

- maximum visibility for your research: over $100 \mathrm{M}$ website views per year

At $\mathrm{BMC}$, research is always in progress.

Learn more biomedcentral.com/submissions 